\title{
STRATEGI PEMASARAN PAKET WISATA FULL DAY DI PT. TOUR EAST INDONESIA
}

\author{
Putu Geni Jaya Ksamawan \\ I Made Kusuma Negara \\ I Putu Sudana \\ Email : genijaya@rocketmail.com \\ PS. S1 Industri Perjalanan Wisata \\ Fakultas Pariwisata UNUD
}

\begin{abstract}
The development of increasing tourist arrivals to Bali led to the development of business and tourism in the world of business, one business trip in Bali. PT. Tour East Tours and Travel is the one of the travel agents in Bali in this to win the competition with other companies, the need for proper marketing strategy and correct. This study aims to determine the marketing strategy Full Day tour packages PT. Tour East Indonesia and what strategies can be implemented in the PT. Tour East Tours and Travel to boost sales of tour packages to tourists as well as winning the competition with other companies.

In this study using Qualitative descriptive data analysis techniques combined with a SWOT analysis to figure out what the right strategy is used to market tour packages Full Day of PT. Tour East Indonesia. Based on the SWOT matrix analysis obtained a marketing strategy that can be applied to PT. Tour East Tours and Travel is a strategy creation and development of tourism products, increased promotion strategies, human resource development strategy, market segmentation strategy development, and strategies for improving the quality of products and services. From the results of this study can be given advice to the PT. Tour East Tours and Travel is improving service process management and define market segments and maintain the image of the internal and external environment, while maintaining a cooperative relationship, and held training to staff meetings
\end{abstract}

Keywords: Marketing Strategy, Package Tour.

\section{PENDAHULUAN}

Perkembangan pariwisata di Bali telah mengalami kemajuan yang sangat pesat baik dari segi kualitas maupun kuantitasnya. Hal ini dapat dilihat dari semakin berkembangnya sarana dan prasarana pariwisata seperti akomodasi, transportasi, fasilitas rekreasi, teknologi informasi, komunikasi dan atraksi wisata. Melihat peluang yang besar dalam dunia pariwisata, hal ini menyebabkan semakin banyaknya lahan bisnis dan usahausaha yang berhubungan dengan pariwisata terkait dengan berbagai kebutuhan wisatawan terutama selama berada di Bali, salah satunya adalah usaha agen perjalanan wisata yang sering disebut dengan travel agent.
Travel agent merupakan perantara bagi perusahaan-perusahaan industri pariwisata dengan wisatawan, oleh karena itu peranannya dalam sektor pariwisata sangat berarti terutama bagi daerah-daerah yang sering dikunjungi oleh wisatawan seperti Bali. Banyaknya objek wisata dan atraksi-atraksi pariwisata yang ada di Bali membuat semakin berkembangnya usaha travel agent dalam memberikan pelayanan jasa maupun produk kepada wisatawan. PT. Tour East Tours and Travel yang merupakan salah satu agen perjalanan atau biro perjalanan wisata yang ada di Bali yang menjual produk dan pelayanan jasa kepada wisatawan. Produk dan jasa yang di tawarkan adalah kemasan paket wisata, adapun beberapa jenis kemasan paket 
wisata yang di jual oleh PT. Tour East and Travel yaitu city tour, half day tour, maupun full day tour. Dari sekian kemasan paket wisata yang di jual, kemasan paket wisata full day tour merupakan salah satu kemasan yang tingkat penjualannya mengalami fluktuasi, sehingga untuk tetap menjaga tingkat penjualan kemasan paket wisata full day kepada wisatawan tetap tinggi dan stabil maka diperlukanlah suatu strategi pemasaran.

Dalam pemasaran kemasan paket wisata full day yang dimiliki PT. Tour East Tours and Travel pastinya harus ada strategi pemasarannya untuk membuat para wisatawan tertarik mengambil paket wisata tersebut dan menggunakan jasa perusahaan sehingga tercapai tujuan yang diharapkan oleh perusahaan. Guna mendalami fenomena latar belakang di atas penelitian ini dilakukan dengan tujuan untuk menciptakan strategi dan program pemasaran untuk menarik wisatawan agar mengunakan jasa PT. Tour East Indonesia.

\section{TINJAUAN PUSTAKA}

Menurut Porter dalam (Rangkuti, 2004:4) strategi adalah suatu alat yang sangat penting untuk mencapai keunggulan bersaing. Senada dengan itu, Hamel dan Pharalad juga mengatakan strategi merupakan tindakan yang bersifat incremental (senantiasa meningkat) dan terus-menerus, dilakukan berdasarkan sudut pandang tentang apa yang diharapkan oleh pelanggan di masa depan (Rangkuti, 2004:4).

Menurut Wahab (1997:27) pemasaran pariwisata adalah suatu proses manajemen yang dilakukan oleh organisasi kepariwisataan nasional atau industri pariwisata untuk menentukan wisatawan actual dan profesional, mengadakan komunikasi dengan mereka untuk menentukan serta mempengaruhi keinginan, kebutuhan, motivasi, kesukaan dan ketidaksukaan pada daerah-daerah lokal, regional, nasional dan internasional.

Menurut Yoeti (2001a: 112), paket wisata adalah tour yang direncanakan dan diselenggarakan oleh suatu travel agent atau tour operator atas resiko dan tanggung jawab sendiri dimana acara, lama waktu tour, tempat mana yang akan dikunjungi, akomodasi, transportasi, serta makanan dan minuman dalam suatu harga yang sudah ditentukan. Paket wisata ini merupakan hasil kombinasi dan berbagai komponen jasa wisata dan diberi tarif tunggal, sehingga harga dari masingmasing komponen tidak diketahui oleh pembeli atau wisatawan.

SWOT menurut Sutojo dan Kleinsteuber (2002: 8) adalah untuk menentukan tujuan usaha yang realistis, sesuai dengan kondisi perusahaan dan oleh karenanya diharapkan lebih mudah tercapai. SWOT adalah singkatan dari kata-kata Strength (kekuatan), Weaknesses (kelemahan), Opportunities (peluang) dan Threats (ancaman).

Bauran Pemasaran adalah salah satu konsep utama dalam pemasaran modern. Kotler (1989:63) menyatakan bahwa bauran pemasaran adalah perangkat variable pemasaran terkontrol yang perusahaan gabungan untuk menghasilkan tanggapan yang dikehendaki perusahaan dari pasar sasaran. Dalam pemasaran barang atau produk terdapat 4 variable yaitu produk, price, promotion, dan place. Namun dalam pemasaran jasa perlu adanya penambahan tiga $\mathrm{P}$ lagi dalam bauran pemasaran yang meliputi: personal, physical, dan process. Sehingga dalam penjualan produk dan jasa perlu memiliki kombinasi terbaik dari ketujuh bauran pemasaran dalam jasa tersebut sehingga dapat menyesuaikan dengan lingkungan pasar.

Menurut R.S Darmajati (1995) Travel Agent adalah perusahaan yang khusus mengatur dan menyelenggarakan perjalanan dan persinggahan orang-orang termasuk kelengkapan perjalanannya dari suatu tempat ke tempat lainnya baik di dalam negari, dari dalam negeri, ke luar negeri atau dalam negeri itu sendiri. Dalam hal ini travel agent memiliki ruang lingkup kegiatan usahanya meliputi penjualan paket tour, pelayanan pemesanan akomodasi dan sarana pariwisata, mengurus dokumen perjalanan, dan pelayanan check in dan check out dari hotel ke bandara dan sebaliknya.

\section{METODE PENELITIAN}

Penelitian ini dilaksanakan di PT. Tour East Indonesia yang terletak di Jl. Pulau Komodo 20, Denpasar Bali. Penelitian mengunakan DOV yang berdasarkan pada unsur-unsur dalam strategi pemasaran meliputi segmentasi, targeting dan positioning dan dipadukan dengan bauran pemasaran (marketing mix). Pengumpulan data pada 
penelitian ini menggunakan metode observasi, wawancara, dan studi kepustakaan, disamping itu penelitian ini menentukan informan dengan mengambil sampel dari orang-orang yang berkompeten untuk menjawab setiap pertanyaan yang berhubungan dengan Strategi Pemasaran Paket wisata Full Day di PT. Tour East Indonesi. Analisis yang digunakan adalah analisis deskriptif kualitatif yaitu dengan menggunakan pendekatan SWOT dan kondisi bauran pemasaran atau marketing mix pada PT. Bali Jaya Citra Tours and Travel.

\section{HASIL DAN PEMBAHASAN}

Berdasarkan analisis kekuatan dan kelemahan dari faktor internal dan peluang, serta ancaman dari faktor eksternal PT. Tour East Tours and Travel yang di kaji dengan analisis SWOT, maka dapat ditemukan suatu strategi pemasaran yang dapat diterapkan pada PT. Tour East Indonesia sebagai berikut :

1. Strategi Strength Oppertunities (SO) adalah strategi yang memanfaatkan kekuatan perusahaan atas peluang dari lingkungan luar. Dari strategi SO ini terciptalah sebuah strategi penciptaan dan pengembangan produk wisata. Adapun program yang dapat dilakukan yaitu:

a. Menciptakan produk wisata yang bervariasi yaitu paket wisata yang memiliki ciri yang berbeda dari biasanya, seperti paket wisata rohani, tracking di persawahan, memasak dan mencoba masakan khas daerah khas Bali itu sendiri disamping memberikan pengalaman wisatawan terhadap keasrian dan kondisi alami pedesaan di daerah Bali .

b. Membuat beberapa kemasan paket wisata dengan harga yang terjangkau dan menarik seperti memberikan diskon dan harga spesial saat tahun liburan kepada wisatawan

2. Strategi Weakness Opportunities (WO) adalah strategi yang meminimalkan kelemahan dengan memanfaatkan peluang yang ada. Strategi yang dapat dilakukan dalam kondisi ini adalah strategi peningkatan promosi dan SDM. Adapun program yang dapat dilakukan yaitu:

a. Memperbaiki dan memanfaatkan promosi lewat web dari perusahaan dengan baik dengan membuat web terlihat lebih menarik, serta tetap selalu memberikan informasi terupdate dan menarik sehingga wisatawan tertarik untuk mecoba kemasan paket wisata yang dijual.

b. Meningkatkan promosi melalui brosur, majalah pariwista, serta TV yang memberikan program tourism and information.

c. Mengembangkan kerja sama dengan pihak hotel, restoran, akomodasi outbound dan inbound, serta dengan overseas agent.

d. Memberikan breafing kepada staff khususnya kepada para guide sebelum melakukan tour

e. Mengadakan meeting secara berkala yang membahas tentang kinerja perusahaan

3. Strategi Strenght Threats (ST) adalah strategi yang memanfaatkan kekuatan yang dimiliki untuk mengurangi ancaman dari luar. Dengan kekuatan yang dimiliki PT. Tour East Tours and Travel yang dikombinasikan dengan faktor ancaman dari luar maka terciptanya suatu strategi yaitu strategi pengembangan segmentasi pasar. Adapun program yang dapat diterapkan yaitu melakukan segmentasi pasar pada wisatawan baru dengan jumlah kunjungan tertinggi di Bali, seperti wisatawan Eropa dan Asia maupun wisatawan domestik.

4. Strategi Weakness Threats (WT) adalah strategi yang mengurangi kelemahan dengan menghindari ancaman yang ada di luar. Dengan kelemahan yang dimiliki PT. Tour East Tours and Travel dan adanya ancaman dari luar maka ditempuhlah suatu strategi meningkatkan kualitas produk dan jasa. Adapun program yang dapat diterapkan yaitu:

a. Memberikan kesan yang aman, nyaman dan menarik saat melakukan tour, seperti mengajak wisatawan bernyanyi dengan lagu-lagu yang sedang populer atau mendengarkan lagu saat perjalanan .

b. Menyajikan snack atau bingkisan yang isinya makanan ringan dan buahbuahan khas daerah Bali kepada wisatawan saat dalam perjalanan menuju objek wisata sehingga hal ini 
akan menjadi daya tarik tersendiri bagi wisatawan.

c. Mengkombinasikan paket wisata yang telah ada dengan kemasan paket wisata baru yang sedang banyak dimintai wisatawan. Dengan mengkombinasikan kemasan paket wisata full day yang sudah ada dengan kemasan paket wisata rohani atau alam.

\section{SIMPULAN DAN SARAN Simpulan}

Berdasarkan hasil pembahasan yang telah diuraikan sebelumnya dan hasil analisis SWOT, maka dapat disimpulkan strategi dan program pemasaran paket wisata yang dapat diterapkan di PT. Tour East Tours and Travel yaitu :

1. Strategi penciptaan dan pengembangan produk wisata yang dilaksanakan dengan program menciptakan paket wisata yang bervariasi dengan harga yang terjangkau dan menarik.

2. Strategi peningkatan promosi dan SDM, program yang dapat ditempuh dengan memanfaatkan promosi lewat media elektronik dan media cetak seperti web, channel parwisata di Tv, brosur dan majalah pariwisata serta mengembangkan kerjasama dengan industri pariwisata lainnya dan melakukan breafing kepada staff serta meeting secara berkala.

3. Strategi pengembangan segmentasi pasar. Strategi ini dapat ditempuh dengan program pengembangan pangsa pasar baru dengan melakukan segmentasi pasar pada wisatwan mancanegara dan domestik.

4. Strategi meningkatkan kualitas produk dan jasa, program yang dapat dilaksanakan yaitu memberikan kesan yang aman, nyaman dan menarik saat melakukan tour dan mengkombinasikan paket wisata yang telah ada dengan kemasan paket wisata baru.

\section{Saran}

Berdasarkan kesimpulan diatas, ada beberapa hal yang perlu disarankan adalah :

1. Meningkatkan sektor transportsai perusahaan dengan berusaha agar memiliki transportasi sendiri sehingga dapat penggunakan transport akan lebih efektif dan efesian tanpa harus mencari transport keluar .

2. Tetap menjaga hubungan kerjasama dengan agen-agen perjalanan saat ini seperti mengadakan gathering (pertemuan) serta menjalin hubungan kerjasama yang baru dengan agen-agen perjalanan baik di dalam maupun di luar negeri.

3. Setiap bulannya didakan pelatihan yang bertujuan untuk lebih meningkatkan pengetahuan dan keahlian agar dapat memberikan pelayanan yang lebih baik kepada tamu yang menggunakan jasa PT. Tour East Indonesia.

\section{DAFTAR PUSTAKA}

Darmadjati, R.S. 1995. Istilah-istilah Dunia Pariwisata. Jakarta : Pradnyamita.

Kothler Philip. 1989. Dasar-dasar Pemasaran. Jakarta PT. Prenhallindo.

Rangkuti, Freddy. 2002. Analisis SWOT Teknik Membedah Kasus Bisnis. Jakarta: Gramedia Pustaka Utama.

Sutojo, dan F. Kleinsteuber, 2002, Strategi Manajemen Pemasaran, seri manajemen No. 6, cetakan pertama, Penerbit : Damar Mulia Pustaka, Jakarta

Wahab, Salah. 1997. Pemasaran Pariwisata. Jakarta : Pradnya Paramita. 